\title{
eCommons@AKU
}

School of Nursing \& Midwifery

Faculty of Health Sciences

February 2014

\section{Harassment: A challenge at workplace}

Muhammad Younas

Aga Khan University

Salma Rattani

Aga Khan University, salma.rattani@aku.edu

Follow this and additional works at: https://ecommons.aku.edu/pakistan_fhs_son

Part of the Bioethics and Medical Ethics Commons, Mental and Social Health Commons, and the Nursing Commons

\section{Recommended Citation}

Younas, M., Rattani, S. (2014). Harassment: A challenge at workplace. i-manager's Journal on Nursing, 4(1), 35-39.

Available at: https://ecommons.aku.edu/pakistan_fhs_son/91 


\title{
HARASSMENT: A CHALLENGE AT WORKPLACE
}

\author{
By \\ MUHAMMAD YOUNAS * \\ SALMA RATTANI ** \\ * MScN student, Aga Khan University Karachi, Pakistan. \\ ** Assistant Professor, Aga Khan University School of Nursing and Midwifery, Pakistan.
}

\begin{abstract}
Health care professionals are deeply involved in caring for the human life and during this process, they come in a close contact with the care recipients. This, at times, positions the health care professionals in a vulnerable situation including workplace harassment which is an offensive verbal or physical act and comprises of an unwanted behavior or advancement or demand for sexual and other favors. This conduct creates an intimidating, unfriendly, and offensive work environment (Sigal, 2006). Consequently, it impacts on care providers' performance, quality care and their retention in the system. Hence, it is important that the health care personnel should be provided with a safe and secured environment and their respect, dignity and honor should be maintained. Additionally, in-case of any mishaps, the perpetrator should be dealtaccordingly.
\end{abstract}

Keywords: Harassment, Health Care Providers, Nurses, Nursing.

\section{INTRODUCTION}

\section{Types of Harassment}

The word harassment covers a wide range of offensive behaviors and comments including physical, verbal, bullying, racial, and religious harassment. The types of workplace harassment are very well defined by a UNISON guide (UNISON, 2008). It defines racial harassment as discrimination of employees throughout the workplace on the basis of their race. Moreover, age harassment is defined as an unfair behavior with employees regarding benefits and promotion because they are considered as too old or too young. Another UK's council Acas (Advisory, Conciliation and Arbitration Service, 2005) defines religious harassment as to discriminate directly against anyone, and to treat them less favorably than others because of their religion or belief. Further, it says to discriminate indirectly against anyone i.e. to apply a criterion, provision or practice which disadvantages people of a particular religion or belief. Somani and Khowaja (2012) mentioned that there are a number of reported and unreported cases in which nurses experience rape, unwanted sexual conducts, workplace bullying, and physical violence from patients, their family members and other healthcare professionals.

Sexual harassment itself covers a vast area, rangeing from an unwanted verbal comment to the use of slang language and form a non-sexual bodily touch to an intentional touch of sexual engagement. According to Ramsaroop and Parumasur (2007), sexual harassment is the sexual advancement, request for sexual favors, sexually verbal or physical conduct which must be unwelcomed. Sexual harassment is divided into two types. Quid pro quo sexual harassment, in which a manager or a supervisor demands or requests sexual favors in exchange for some employment benefit, and hostile sexual harassment, in which employees are exposed to sexual harassment by co-workers other than managers and supervisors (Ramsaroop \& Parumasur, 2007).

\section{Scenario}

In an in-patient unit of a health care setting, a 24 years old female registered nurse was assigned to a 70 years old female patient with an end stage oncology disease having a Glasgow Coma Scale (GCS) of 5/15. As per routine, around $10 \mathrm{AM}$ for administration of medication, the nurse entered in the patient's room. A male attendant was present in the room sitting on a chair. After greeting, the nurse was involved in patient care. The attendant initially was staring at the nurse and then he started asking about the medication and patient's condition. Following her professional responsibility, the nurse responded to his 
queries, but suddenly she noticed that attendant standing from his chair came near the nurse and stood with the intention to grab her hand. The nurse protected herself and called for help which was received immediately. Overcoming such situations require support from colleagues and the management, in the absence of which, there could be drastic consequences. In light of this scenario, this paper aims to discuss the management of workplace harassment.

\section{Management of workplace Harassment}

To break the silence and to make the workplace harassment free, all we need is to bring change. Manager's job is to deal with problems and issues on a daily basis. Some problems are simple and can be solved right away, while others are complicated and challenging and require a lot of homework, planning and strategies to deal with. Workplace harassment is a problem of one of its kind with a complex and complicated nature, but by adopting and applying some strategies and policies, it is manageable to a greater extent. For the management of this problem, "Ronald Lippitt's change theory" will guide us in a much better way. According to Mitchell (2013), the pioneer of change theory is perhaps Kurt Lewin in 1951 who identified three stages Unfreezing, Moving and Refreezing; this theory was further modified by Rogers in 2003, and described five phases of change that are: Awareness, Interest, Evaluation, Trial and Adoption.

\section{Application of Ronald Lippitt's Change Theory to Deal with} Workplace Harassment

Ronald Lippittin (1958) generated the theory of change in seven phases which is actually a modified form of Lewin's theory. The seven phases of Lippitt's change theory are: diagnosing the problem, assess motivation and capacity for change, assess change agent's motivation and resources, selecting progressive change objectives, choosing the appropriate role of changing agent, maintaining change and terminating the helping relationship (Roussel, 2013,p. 135-136). For elaboration, appendix 1 can be referred. Furthermore, according to Roussel (2013) Lippitt added seven stages to Lewin's original theory ( $\mathrm{p} .135$ ) the reason for selecting Lippitt's change theory is, because these steps actually help us describe a problem in much detail, and will help us to overcome this issue properly.

\section{Phase 1:}

Phase one is about diagnosing the problem. As managers, first of all, we actually have to look what the problem is all about and then we have to look into the severity of the problem. The scenario above is just a glimpse of what is happening to the nurses all around on a routine basis. Few of the cases have been highlighted and a number of cases go unnoticed, it is just like an ice berg, where we can just see the tip of it. Somani and Khowaja (2012) have mentioned that most the time workplace harassment goes unnoticed in most of the healthcare institutions. It is the manager's prime responsibility to take immediate action in order to ensure the employee's safety. Moreover, to explore the problem at the same time, we also have to involve other multidisciplinary teams including safety and security.

\section{Phase 2:}

Phase two is about Assessing motivation and capacity for change. In this stage, we have to build up the confidence level of our employees. Nurses, most of the time, lack the confidence to share the bad events that happen to them. This lack of confidence and remaining silent limits our capacity for bringing the change. As according to Somani and Khowaja (2012), in most of the health care organizations, cases of workplace violence are not highlighted as nurses have feared that, they would be blamed by the people for the act which happened at work with them. The managers do not encourage the nurse to share and speak, which could help in building confidence in nurses. Furthermore, Shiwani and Elenin (2010) stated that, many victims of workplace harassment including doctors, nurses and other trainees are not sure how to seek assistance and very often feel helpless.

\section{Phase 3:}

For the third phase i.e. assessing change agent's motivation and resources, our managers are, of course the front line leaders, but we also have to take all of our employees in a loop. According to Roussel (2013), the change agent could be internal or external to the organization or institution (p. 136). Here, it will not be a oneman show, managers definitely have to take the lead and, 
nurses and other health care professionals have to show their confidence and that's how they all will be internal changing agents. If the nurse could have spoken with the support of the manager, then the situation could be different and the perpetrator would realize his wrong deed. On the other hand external changing agents will be government initiatives, policies and legislation against workplace harassment. Moreover, as managers, we have to raise the issue, to make the offender and their supporters realize the significance of the problem.

\section{Phase 4:}

In the fourth phase i.e. select progressive change objectives, the managers take a stand, plans are made and individuals are assigned some roles and responsibilities. Each and every health care professional must know their assigned responsibilities. For long lasting effects the set goals must be realistic and achievable.

\section{Phase 5:}

The fifth phase is about choosing an appropriate role of the change agent. The internal change agents definitely should have certain guidelines and there comes the policy adaptation. At institutional level, we managers have to adopt and generate proper policies. Workplace harassment occurs on a routine basis, because either there is no policy at all to prevent it or even if a policy exists, then there is a lack of implementation. According to Shiwani and Elenin (2010), the health department in Pakistan might have an existing up-to-date policy, but is not accessible to the public at all. Shiwani \& Elenin (2010) also stated that most of Government employees have never even heard of such a policy. Few of the private sectors have defined policies to control work place harassment. According to Somani and Khowaja (2012) in Pakistan some of the health care settings, such as The Aga Khan University Hospital (AKUH) maintains a zero tolerance policy. According to this policy, the hospital does not tolerate the violent behavior of any of the offences composed on Patients, family members, visitors, and even employees.

\section{Phase 6:}

The sixth phase is about maintaining the change. Now the change that we want to bring will only be possible after proper implantation and adherence to the adopted policies. This really is the most important and challenging step i.e. to apply what we have planned. A policy without implementation will be just a formality and for the sake of documentation. Our managers have to make sure the application of policies to control work place harassment regardless of the social status of the perpetrator. However, in most of the cases, situation is such that the young female health care professionals are among the groups of professionals who are susceptible to 'workplace violence', but there are no arrangements to prevent them from becoming victims of such violence. (Dawn Newspaper 2012-08-04).

\section{Phase 7:}

The seventh phase which is the last phase is about terminating the helping relationship. At first look this phase sounds odd, because it talks about withdrawal of the change agent at this specific point, but Roussel (2013) further explains that the change agent will remain available for advice and reinforcement (p. 136). Hence, the nurse manager needs to be available to support and guide the staff if needed.

\section{Effects of Workplace Harassment}

Workplace harassment has devastating effects on the outcome of an organization. Problems like workplace harassment have always given a hard time to the managers and nurses in hospital, where on one hand we have patient health, and on the other hand nurses have to maintain their dignity and honor. As a result, nurses cannot perform their task with concentration and dedication having implication for quality care and on retention of nurses. According to Naveed, Tharani and Alwani (2010), both the organization and individual suffers, if the employees are not safe and satisfied. Furthermore, the reputation of an organization gets damaged. On the other hand, if managers take initiatives, these problems can be handled to a great extent. As according to Vijayasiri (2008) an organization interventions to stop harassment it can also help to overcome other problems such as quitting a job or absenteeism, outcomes that are not in favor of the employee as well as the organization.

\section{Leadership Style to Overcome Workplace Harassment}

For the sustainability of the change and to maintain the 
policies for controlling the workplace harassment managers have to adopt a proper leadership style. Additionally, it is important that through involving the health care personnels, should be imbibed a feeling of "We" among the group members. This goal could be achieved through selection of the right kind of leadership style and democratic leadership style may create such feelings of being one. This style could provide autonomy, freedom and respect to individuals to participate in the process of decision making. Mitchell (2013) stated that the democratic leadership style is beneficial, when we need cooperation and coordination between the groups. This style provides team members with strength, courage and support to deal with unwanted acts in a better way.

\section{Recommendations}

Following are some recommendations to overcome workplace harassment.

- Harassment has no place in the working environment and should not be tolerated at any cost.

- A Zero tolerance policy should be adopted and its proper implementation can provide a safe workplace environment.

- Awareness regarding workplace harassment should be included in Nursing curriculum.

- A system of incident reporting should be introduced and compliance with the system should be encouraged and monitored.

- It is the responsibility of each and every person from managers to subordinates to play their part for control of workplace harassment.

- Nurses should be empowered and should not be afraid to raise their voice against harassment and they should be supported by managers for successfully of controlling the harassment.

- Managers should use leadership styles that provide safety and security to the staff and they should be privileged for maintaining their dignity, respect and honor.

\section{Conclusion}

To conclude, workplace harassment is and will remain as a serious problem for health care personnels including nurses. Hence, it is important that proper initiatives should be taken to overcome this issue. Without proper management and guidance, nurses and other health care workers will continue to be the victims. While looking at the societal view about nursing, establishment of harassment-free workplace environment may be difficult but not impossible.

\section{References}

[1]. Advisory, Conciliation and Arbitration Service, (2005). Religion or belief and the workplace. Retrieved from Acas Publications website: http://www.acas.org.uk for Nurse Administrators (4th ed.). Sudbury, U.S.A: Jones and Bartlett.

[2]. Dawn News (2012, August 4). Nurses exposed to harassment as law remains unenforced. Dawn News [Karachi]. Retrieved from http://www.dawn.com/news/ 739758/nurses-exposed-to-harassment-as-law-remainsunenforced

[3]. Mitchell, G. (2013). Selecting the best theory to implement planned change. Nursing Management, 20(1), 32-37.

[4]. Naveed, A., Tharani, A., \&Alwani, N. (2010). Sexual Harassment at Work Place: Are You Safe? J Ayub Med CollAbbottabad, 22(3), 222-224.

[5]. Ramsaroop, A., \& Parumasur, S. B. (2007). The Prevalence and Nature of Sexual Harassment in the Workplace: A Model for Early Identification and Effective Management Thereof. Journal of Industrial Psychology, 3(2), 25-33.

[6]. Roussel, L. (2013). Management and leadership for nurse administrators. Burlington, MA: Jones \& Bartlett Learning.

[7]. Shiwani, M. H., \& Elenin, H. (2010). Bullying and harassment at workplace: Are we aware? J Pak Med Assoc, 60(7), 516-517.

[8]. Sigal, J. (2006). International Sexual Harassment. Ann. N.Y. Acad. Sci, 1087, 356-369. doi: 10.1196/ annals. 1385.008.

[9]. Somani, R. K., \& Khowaja, K. (2012). Workplace violence towards nurses: A reality from the Pakistani context. Journal of Nursing Education and Practice, 2(3), 148-153.

[10]. UNISON (2008). Harassment at Work - a UNISON guide. 
Appendix 1

Ronald Lippitt's seven phases in change theory

Phasel. Diagnose the problem

Phase 7. Teminate

helping relationship

Phase2.Assessing motivation and capacity for change

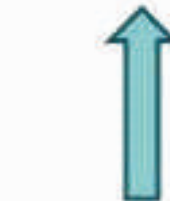

Phase 6. Maintain change

Phase3. Assess change agent's motivation and resources

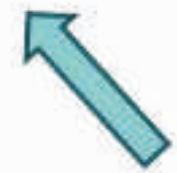

Phase5. Choose appropriate role of the change agent

Phase4. Select progressive change objective

ABOUT THE AUTHORS

MScN student, Aga Khan University Karachi pakistan.

Salma Rattani is currently working as the Assistant Professor, Aga Khan University School of Nursing and Midwifery, Pakistan. She received MSCN graduate in the Aga University School of Nursing and she is also the director of BScNProgramme Aga Khan University School of Nursing and Midwifery. 